\title{
COMPARISON OF ACTUAL AND PREDICTED TOOTH WIDTHS OF CANINES AND BICUSPIDS USING THE BUCCO-LINGUAL WIDTH METHOD IN ANGLE CLASS I CASES
}

\author{
Ahmed Maher Fouda*
}

\begin{abstract}
Objectives: To determine the validity of predicting the combined widths of permanent canines and bicuspids from the bucco-lingual widths of the first permanent molars according to AboulAzm and Fouda method in Angle class I cases. Material and Methods: Comparison was done between actual and predicted values of permanent canines and caspids from 22 dental casts. The casts represented Angle class I crowded anterior teeth. The casts related to female patients of age range 14- 16 years. Results: Only upper left side showed significant difference with Angle class I cases. Conclusion: This method is reliable by $75 \%$ to Abou Elazm and Fouda method in prediction of the tooth size material in Angle class I cases.
\end{abstract}

\section{INTRODUCTION}

Space analysis in the mixed dentition period is a very important step of orthodontic diagnosis and treatment planning ${ }^{(1)}$. It is a precious tool in determining whether this treatment planning entails eruption guidance, serial extraction or just periodic observation of the patients ${ }^{(2)}$. Space analysis allows for the determination of valuable space in the canine and bicuspid areas in the upper and lower arches ${ }^{(3)}$. Tooth size prediction of the unerupted canines and bicuspid forms the essential part in the mixed dentition analysis ${ }^{(4)}$. For estimation of the tooth widths of canines and bicuspids in the mixed dentition, three ways have been used in measurement of unerupted teeth on radiographs ${ }^{(5)}$; relating erupting teeth to unerupted teeth through regression equations ${ }^{(6)}$, and from eruption teeth and radiographs of unerupted teeth ${ }^{(7)}$. In 1989, a novel approach of mixed dentation analysis by Abuol-azm and Fouda was documented ${ }^{(8)}$. This novel approach stated that, in the upper arch the combined widths of the canine and bicuspids on one side equal the bucco-lingual width of the first permanent molar multipled by 2 and minus 1 from the total value obtained. In the lower arch, the mesiodistal widths of canine and bicuspids on one side equal the buccolingual width of the first permanent molar on that side multiplied by 2 . Crowding in the dental arches is the lack of space for good alignment of teeth ${ }^{(9)}$. In presence of both sexes with crowding in

\footnotetext{
* Lecturer of Orthodontics، Faculty of Dentistry-Mansoura University
} 
the anterior part of the dental arches, the dominant characteristics is the greater mesiodistal diameters of upper and lower incisors ${ }^{(10)}$. There are plenty of methods used to estimate the tooth size and the arch length ${ }^{(14-16)}$. The aim of the present study was to compare the actual and predicted combined widths of canines and bicuspids. The predicted value of the canines and bicuspids was obtained from the buccolingual width of the first permanent molars in references to Aboul-Azm and Fouda novel approach of mixed dentition analysis ${ }^{(8)}$. From the correlation between the actual and predicted values of canines and bicuspids validity was obtained. Validity refers to ability to truly measures what is intended to be measured, it was ascertained from measures of mean differences and correlation between actual and predicted combined widths of canines and bicuspids ${ }^{(5)}$.

\section{MATERIAL AND METHODS}

Twenty-one dental casts for female patients were selected from the archive of author's private clinic. The data of the patients were conditional and their data were represented in a manner not reflected identification of any patient. The age ranged from 14-16 years. The dental casts of this study were Angle class I with crowded anterior teeth with all permanent teeth erupted except the third molars. The inclusion criteria were: no previous orthodontic treatment, no mesiodistal caries, no cavities, no restorations, no fractures, no congenital tooth defects and no tooth wear ${ }^{(11)}$. The mesiodistal width of canines and bicuspids and the bucco-lingual width of the first permanent molars were measured. A digital caliper*, which read to the nearest $0.01 \mathrm{~mm}$ was used to record the measurement according to the method described by Jensen et al ${ }^{(12)}$. The mesiodistal widths of the canines and bicuspids were approach by getting the greatest distance between the contact points on their proximal surfaces. The sliding caliper was held parallel to the occlusal and vestibular surfaces. This technique was employed to the bicuspids which were in normal position. In cases of infra-occluded canines, their mesiodistal widths were obtained by measuring between the points where contact with the neighboring teeth normally should occur. The buccolingual width of the first permanent molar was measured at the largest bucco-lingual measurement where the caliper was held parallel to the occlusal surfaces of the molars. Five casts were re-measured by the author for accuracy and to exclude any errors.

\section{Statistical analysis}

IBM SPSS (Armonk, NY: IBM Corp) software package version 20.0 was used to analyze the data. Verification is done by The KolmogorovSmirnov test to ensure the normality of distribution Quantitative data were described using range (maximum and minimum), median, standard deviation and mean. 5\% level was judgment for the significance of the obtained results.

The used test was

1 - Paired t-test

For normally distributed quantitative variables, to compare between groups.

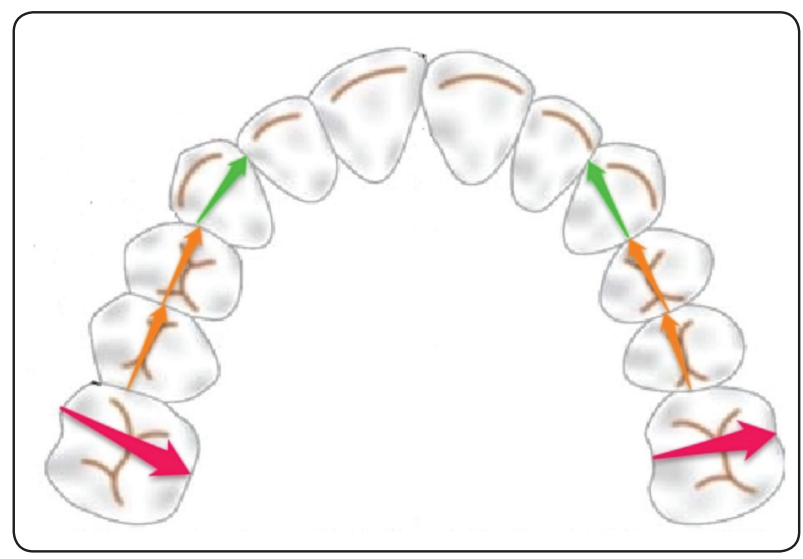

Fig (1): diagram shows measurements done on the casts 


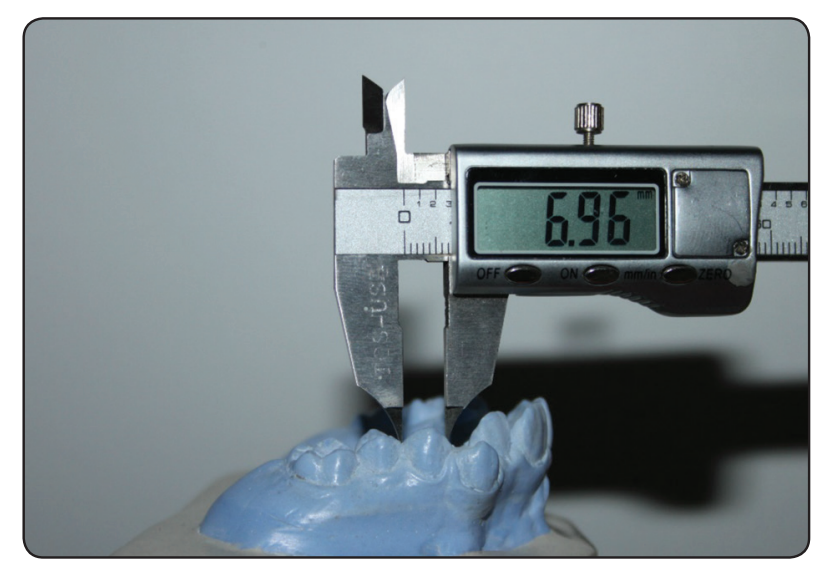

Fig (2): digital caliper used in measurements on the dental cast

\section{RESULTS}

TABLE (1): Descriptive analysis of the studied cases according to buccolingual width measurement, predicted and actual width $(\mathrm{n}=21)$

\begin{tabular}{|c|c|c|c|}
\hline & \begin{tabular}{|c|} 
Buccolingual \\
width \\
of the $1^{\text {st }}$ \\
permanent \\
molar \\
\end{tabular} & $\begin{array}{c}\text { "Predicted } \\
\text { width } \\
\text { of canine and } \\
\text { bicuspid }\end{array}$ & $\begin{array}{c}\text { Actual width } \\
\text { of canine and } \\
\text { bicuspid }\end{array}$ \\
\hline Upper right side & & & \\
\hline Min. - Max. & $10.20-11.90$ & $19.40-19.40$ & $20.50-24.80$ \\
\hline Mean $\pm \mathrm{SD}$ & $11.29 \pm 0.46$ & $21.59 \pm 0.91$ & $22.22 \pm 1.11$ \\
\hline Median & 11.40 & 21.80 & 22.0 \\
\hline $\mathrm{t}(\mathrm{p})$ & & \multicolumn{2}{|c|}{$2.399^{*}\left(0.026^{*}\right)$} \\
\hline Mean diff. & & \multicolumn{2}{|c|}{-0.63} \\
\hline \multicolumn{4}{|l|}{ Upper left side } \\
\hline Min. - Max. & $9.80-12.10$ & $|18.60-23.20|$ & $20.40-23.10$ \\
\hline Mean \pm SD & $11.19 \pm 0.52$ & $21.38 \pm 1.04$ & $21.54 \pm 0.77$ \\
\hline Median & 11.20 & 21.40 & 21.50 \\
\hline $\mathrm{t}(\mathrm{p})$ & & \multicolumn{2}{|c|}{$0.698(0.493)$} \\
\hline Mean diff. & & \multicolumn{2}{|c|}{0.27} \\
\hline \multicolumn{4}{|l|}{ Lower right side } \\
\hline Min. - Max. & $9.80-11.40$ & $19.60-22.80$ & $20.20-22.80$ \\
\hline Mean \pm SD & $10.80 \pm 0.35$ & $21.61 \pm 0.71$ & $21.34 \pm 0.81$ \\
\hline Median & 10.80 & 21.60 & 21.20 \\
\hline $\mathrm{t}(\mathrm{p})$ & & \multicolumn{2}{|c|}{$1.402(0.176)$} \\
\hline Mean diff. & & \multicolumn{2}{|c|}{-0.16} \\
\hline \multicolumn{4}{|l|}{ Lower left side } \\
\hline Min. - Max. & $|9.60-11.50|$ & $|19.20-23.0|$ & $20.0-24.10$ \\
\hline Mean \pm SD & $10.75 \pm 0.45$ & $21.50 \pm 0.90$ & $21.57 \pm 0.96$ \\
\hline Median & 10.90 & 21.80 & 21.50 \\
\hline $\mathrm{t}(\mathrm{p})$ & & \multicolumn{2}{|c|}{$0.250(0.805)$} \\
\hline Mean diff. & & \multicolumn{2}{|c|}{-0.06} \\
\hline
\end{tabular}

$\#:$ Predicted width of $3,4 \& 5=$ Buccolingual width of $6 \times 2$ in $\mathrm{mm}$

$t$ : Paired t-test

p: $p$ value for comparing between Predicted width and Actual width

*: Statistically significant at $p \leq 0.05$

\section{DISCUSSION}

The present study was done to determine the accuracy in comparison of the actual and predicted tooth widths of canines and bicuspids using the bucco-lingual width method in Angle class I cases (Aboul-Azm \& Fouda method). Mainly crowding could be divided into acquired or inherited. Crowded erupting permanent incisors may be considered normal if it is improved by growing of the jaws and the tongue posture. Determination of Space analysis is critical in orthodontic treatment. Results from various studies may differs according to the ethnic group, sample size and the methods of the analysis used. If the tooth size is underestimated, this may lead to inadequate space and crowding in the permanent teeth ${ }^{(13)}$. On the other side, unnecessary extraction may result due to overestimation of the tooth size. Dental cast offered easy and helpful patient record to detect any linear changes in the dental arches. In the present study, the upper right side area showed the only statistically significant difference between the actual widths of canines and bicuspids and their predicted widths in the angle class I cases. This mean that the predicted tooth width of the canine and bicuspids was not ideal. On the other hand, upper left side, lower left side and upper left side showed no statistically significant difference, meaning that the predicted widths of the tooth material were close to the actual widths. This agree with Fouda and Aboul-Azm method in tooth size prediction method ${ }^{(8)}$. Fouda and AboulAzm method represent a good diagnostic predictor for the unerupted cuspids and bicuspids. Clinically the molar breadth can be measured in a short time. Bishara et al found that crowding occurred in the incisors area after orthodontic treatment or after the retention period may result from inadequate orthodontic diagnosis and treatment planning (17). This present study proved the valiablity of Fouda and Aboul-Azm method in Angle class I cases by $75 \%$. 
Various techniques used for mixed dentition analysis lie in the interest for the orthodontists to help them to diagnose their cases resulting in proper and ideal treatment.

\section{CONCLUSION}

This method is reliable by $75 \%$ to $1-$ Aboul-Azm and Fouda method in prediction of the tooth size material in An.gle class I cases

Further investigation is needed to verify this method in different modalities of malocclusion

\section{REFERENCES}

1- Tikku T, Khanna R, Sachan K, Agarwal A, Srivastava K and Yadav P. A new proposed regression equation for mixed dentition analysis using the sum of permanent mandibular four incisors and first molar as a predictor of width of unerupted canine and premolars in a sample of north indian population. J Orthod sci. 2013;2(4): 124-129.

2- AL-Bitar ZB, AL-Omari IK, Sonbol HN, AL-Ahmad HT, Hamdan AM. Mixed dentition analysis in a Jordanian population. Angle Orthod. 2008; 78(4):670-675.

3- Carty O, Creaven V, Hennessy J and AL-Awadhi. A manual for space analysis in the mixed dentition. Ortho Update. 2015; 8:118-125.

4- Thimmegowda U, Divyashree, Nikwlikar KB, Khare V and Prabhakar A. Applicability of tanaka jhonston method and prediction of mesiodistal width of canines and premolars in children. J clin and diagnose Res. 2017; 11(6):16-19.

5- Luu NS, Mandich MA, Tie LD, Kaipature N and FloresMir C. The validity and reliability of mixed dentition analysis methods. Jada. 2011; 142(10):1143-1153.

6- Kondapaka V, Sesham VM, Neela PK and Mamillapall PK. A comparison of seven mixed dentition analysis methods and to evaluate the most reliable one in nalgonda population. J Ind Orthod Soc. 2015; 49(1):3-9.
7- Kadu A, Londhe SM, kumar P, Datana S, Singh M and Gupta N. Estimating the size of unerupted canine and premolars in a mixed indian population. J Dent Res Rev. 2014;1:62-65.

8- Abou - Elazm S and Fouda MA. Size prediction of cuspid and bicuspids via buccolingual breadth of first permanent molar. Egy Orthod Soc. 1989;3(1):69-83.

9- Janosevic M, Filipovic G, Stankovic S and JANJIC OT. Influence of the size of incisors on the occurrence of crowding. Facta Uinversitatis. Series: Medicine and Biology. 2006; 13(1):36-43.

10- Bernabe E, Biostat C, Villanueva KM, Flores-Mir C. Tooth width ratios in crowded and noncrowded dentitions. Angle Orthod. 2004;74(6):765-768.

11- Melgaco CA, Arujo M, Ruellas A, Lacerda S, Magalhaes S, Grossmann S and Jorge K. Tooth size prediction in white Brazilian individuals: applicability of methods. REV Univers Vale do Rio Verde. 2017; 15(1):892-904.

12- Moorrees CF, Thomsen SO, Jensen E and Yen PK. Mesiodistal crown diameters of the deciduous and permanent teeth in individuals. J Dent Res. 1957; 36-39.

13- Sethusa MPS, Brijlall S and Motlob DP. Comparison of two methods of predicting mesiodistal widths of permanent canines and premolars in a sample of black South Africans. Sad J. 2018; 73(1): 31-34.

14- Farrag NM and Awad S. Comparison of study model and digital panoramic radiographic in estimating tooth size and arch length in children. Egy Dent J .2010; 37:1-13.

15- Tanaka MM and Johnston LE. The prediction of the size of unerupted canines and premolars in a contemporary orthodontic population. JADA. 1974; 88: 798-801.

16- Hixon EH and Oldfather RE. Estimation of the size of unerupted cuspids and bicuspids teeth. Angle Orthod. 1958;28(4): 236-240.

17- Bishara SA, Khadivi P and Jackobsen JR. Changes in tooth size - arch length relationship from the deciduous to the permanent dentition: A longitudinal study. AM J Orthod. 1995;108:607-13. 